\title{
Article \\ Effect of High Strain Rate on Adiabatic Shearing of $\alpha+\beta$ Dual-Phase Ti Alloy
}

\author{
Fang Hao ${ }^{1,2}$, Yuxuan Du ${ }^{2, *}$, Peixuan $\mathrm{Li}^{1}$, Youchuan Mao ${ }^{1,2}$, Deye Lin ${ }^{3}$, Jun Wang ${ }^{1}$, Xingyu Gao ${ }^{4}$, \\ Kaixuan Wang ${ }^{2}$, Xianghong Liu ${ }^{2}$, Haifeng Song ${ }^{4}$, Yong Feng ${ }^{1,2}$, Jinshan $\mathrm{Li}^{1}$ and William Yi Wang ${ }^{1, *}$ (1) \\ 1 State Key Laboratory of Solidification Processing, Northwestern Polytechnical University, \\ Xi'an 710072, China; haofang85@163.com (F.H.); peixuan_li@mail.nwpu.edu.cn (P.L.); \\ myc2525@163.com (Y.M.); nwpuwj@nwpu.edu.cn (J.W.); yfeng@c-wst.com (Y.F.); ljsh@nwpu.edu.cn (J.L.) \\ 2 Western Superconducting Technologies Co., Ltd., Xi'an 710018, China; kingsin@c-wst.com (K.W.); \\ xhliu@C-wst.com (X.L.) \\ 3 CAEP Software Center for High Performance Numerical Simulation, Institute of Applied Physics and \\ Computational Mathematics, Beijing 100088, China; lin_deye@iapcm.ac.cn \\ 4 Laboratory of Computational Physics, Institute of Applied Physics and Computational Mathematics, \\ Beijing 100088, China; gao_xingyu@iapcm.ac.cn (X.G.); song_haifeng@iapcm.ac.cn (H.S.) \\ * Correspondence: Eason@c-wst.com (Y.D.); wywang@nwpu.edu.cn (W.Y.W.)
}

check for updates

Citation: Hao, F.; Du, Y.; Li, P.; Mao, Y.; Lin, D.; Wang, J.; Gao, X.; Wang, K.; Liu, X.; Song, H.; et al. Effect of High Strain Rate on Adiabatic Shearing of $\alpha+\beta$ Dual-Phase Ti Alloy. Materials 2021, 14, 2044. https://doi.org/ $10.3390 /$ ma14082044

Academic Editor: Elena Pereloma

Received: 1 April 2021

Accepted: 15 April 2021

Published: 19 April 2021

Publisher's Note: MDPI stays neutral with regard to jurisdictional claims in published maps and institutional affiliations.

Copyright: (C) 2021 by the authors Licensee MDPI, Basel, Switzerland. This article is an open access article distributed under the terms and conditions of the Creative Commons Attribution (CC BY) license (https:/ / creativecommons.org/licenses/by/ $4.0 /)$.
Abstract: In the present work, the localized features of adiabatic shear bands (ASBs) of our recently designed damage tolerance $\alpha+\beta$ dual-phase Ti alloy are investigated by the integration of electron backscattering diffraction and experimental and theoretical Schmid factor analysis. At the strain rate of $1.8 \times 10^{4} \mathrm{~s}^{-1}$ induced by a split Hopkinson pressure bar, the shear stress reaches a maximum of $1951 \mathrm{MPa}$ with the shear strain of 1.27. It is found that the $\alpha+\beta$ dual-phase colony structures mediate the extensive plastic deformations along $\alpha / \beta$ phase boundaries, contributing to the formations of ASBs, microvoids, and cracks, and resulting in stable and unstable softening behaviors. Moreover, the dynamic recrystallization yields the dispersion of a great amount of fine $\alpha$ grains along the shearing paths and in the ASBs, promoting the softening and shear localization. On the contrary, low-angle grain boundaries present good resistance to the formation of cracks and the thermal softening, while the non-basal slipping dramatically contributes to the strain hardening, supporting the promising approaches to fabricate the advanced damage tolerance dual-phase Ti alloy.

Keywords: deformation and fracture; microstructure; adiabatic shear bands; Schmid factor; dual-phase

\section{Introduction}

Titanium (Ti) alloys are widely used in aerospace and biomedicine, attributed to their excellent high specific strength, good corrosion resistance, and high heat resistance [1-3]. In the development of advanced damage-tolerant Ti alloys, it is a challenge to dramatically enhance their mechanical properties under extreme conditions, such as high temperature and pressure, severe corrosion environments, or high loading rates. Recently, defect engineering has been considered as an effective strategy for modifying the local microstructures, properties, and performance of advanced metal materials [2,4-8]. Without changing the chemical composition, the introduction of defects provides more freedom to optimize microstructures and mechanical properties [4,5,8]. In particular, dual-phase materials [9-11] present ultra-strong and ductile behaviors through solid solution strengthening, the grain refinement effect, and precipitation hardening, which excellently deal with the planar defects, including stacking faults, grain boundaries, and phase boundaries. Through combining a high volume fraction of pyramidally arranged non-shearable super-refined $\alpha$ precipitates in the constrained $\beta$ matrix, the ultimate strength of $\alpha+\beta$ dual-phase Ti-15Mo-3Nb-2.7Al$0.2 \mathrm{Si}$ (wt \%) alloy (the $\beta-21 \mathrm{~S}$ or TB8 alloy) can be optimized in the range of $1-2 \mathrm{GPa}$ [12]. Similarly, the $\alpha+\beta$ dual-phase Ti-3Mo-3Cr-2Fe-2Al alloy presents an excellent combination of ultimate tensile strength and ductility at $1324 \mathrm{MPa}$ and 0.37 , respectively [13]. Attributed 
to the twinning induced plasticity (TWIP) and transformation-induced plasticity (TRIP) effects, the strain-transformable Ti alloys display a superior combination of strength, ductility, and strain-hardening [14]. The sliding of $\alpha / \beta$ interfacial and colony boundaries plays the dominant role in the deformation of a newly developed Ti- $0.85 \mathrm{Al}-4 \mathrm{~V}-0.25 \mathrm{Fe}-0.25 \mathrm{Si}-$ $0.15 \mathrm{O}$ alloy [15]. Moreover, in hexagonal close-packed (HCP) structures, the selection of key slip systems is generally controlled by the stacking fault energies in the basal and the prismatic planes, which dominate the slip process to form either twins or dislocations $[2,7,16]$. The Schmid law $[1,16-18]$ provides an efficient approach to estimate the most possible activated slip variants for the given orientation relationships, the tensile direction and the crystallographic orientations, and thus to estimate the corresponding plastic deformation behaviors.

The strain-rate-dependent mechanical properties and structural evolutions should be revealed comprehensively [19-23]. Adiabatic shear bands (ASBs) are obtained at a high strain rate, yielding from the competition between thermal softening and strain/stress-rate hardening within the narrow planar region $[20,24,25]$. Although twinning is the most dominant plastic deformation behavior for HCP structures at ambient temperature, it is suppressed by dislocation gliding at high temperatures, which is for colony microstructures $[17,26,27]$. For instance, in the commercial $\alpha+\beta$ dual-phase Ti-10V-2Fe-3Al alloy with TWIP/TRIP properties, the strain-induced martensite $\alpha^{\prime \prime}$ is treated as a relaxation mechanism at the $\alpha / \beta$ interface [14]. With the enhancement in strain rate from 500 to $1000 \mathrm{~s}^{-1}$, the stress-induced martensitic transformation was observed in the TB8 alloy [28]. At the strain rate of $1000 \mathrm{~s}^{-1}$, multiple deformation mechanisms were comprehensively investigated in Ti-25Nb-3Zr-3Mo-2Sn, presenting the dynamic deformation sequences as $\{332\}<113>$ and $\{112\}<111>$ mechanical twining + stress-induced $\alpha^{\prime \prime}$ and $\omega$ phase transformations + dislocation slip at $293 \mathrm{~K} \rightarrow\{332\}<113>$ and $\{112\}<111>$ mechanical twining + dislocation slip at $573 \mathrm{~K} \rightarrow$ dislocation slip only at $873 \mathrm{~K}$ [29]. The softening behavior of dual-phase Ti17 alloy (Ti-5Al-4Cr-4Mo-2Sn-2Zr) at a high temperature is attributed to the combinations of dynamic recrystallization, dynamic transformation, adiabatic heating, and morphological texture evolution [30]. Instead of thermal softening mechanisms, the microstructure evolutions or transformations play an important role in the initiation of ASB [21,24,31-33]. It is essential to reveal the microstructure-property relationship under dynamic loading in order to develop advanced damage-tolerant Ti alloys. Therefore, the $\alpha+\beta$ dual-phase Ti alloy (Ti-6Al-2Cr-2Mo-2Nb-2Sn-2Zr) fabricated by Western Superconducting Technologies Co, Ltd (Xi'an, China) was utilized to comprehensively reveal the localized features of ASBs in the present work.

\section{Materials and Methods}

In the present work, the hat-shaped specimen [34] of the annealed forging $\alpha+\beta \mathrm{Ti}$ dual-phase alloy was deformed at ambient temperature using split Hopkinson pressure bar (SHPB), which conventionally captures the well-controlled and designed localized shear in the study of large strain and high strain rate deformation. In order to show earlier behaviors of shear localization, a lower shear strain rate of $1.8 \times 10^{4} \mathrm{~s}^{-1}$ was deliberately selected. Three samples were utilized in the SHPB tests, but the one yielding the best results is reported and was analyzed further. Afterward, the standard metallographic procedure was utilized to prepare all samples, which were etched in a solution of $8 \%$ tetrafluoroboric acid for $90 \mathrm{~s}$ for the final characterizations. For the reference state, the static tensile properties were tested at the strain rate of 0.01 based on the national standard of GB/T 228.1-2010. Electron backscattered diffraction (EBSD) analysis was executed on a JEOL 7800F field emission SEM equipped with SymmetryTM (Oxford Instruments, Oxfordshire, UK). The accelerating voltage was $20 \mathrm{kV}$, the probe current was $14 \mathrm{nA}$, the scanning speed was $815 \mathrm{~Hz}$, and the scanning step sizes of 0.15 and $1 \mu \mathrm{m}$ were used for areas of 0.16 and $2.88 \mathrm{~mm}^{2}$, respectively.

In line with the Schmid law $(\tau=\sigma \cos \varphi \cos \lambda)$, the slip system, with either a maximum position or minimum negative $\mathrm{SF}(\mathrm{m}=\cos \varphi \cos \lambda)$, was activated by the largest shear stress 
$(\tau)$. Here, $\lambda$ is the angle between the slip direction and external force $(\sigma)$ and $\varphi$ is the angle between the normal of the slip plane and center axis. Based on the geometry of the hat-shaped specimen [34], the slip plane was fixed by the weakest regions, as presented by a group of planes paralleling to the designed shear region. Therefore, the global $<$ phi $>$ depended on the sample's geometry structure, and $\cos \varphi$ was fixed at $1 / \sqrt{5}$.

\section{Results and Discussion}

\subsection{Microstructure Characterizations}

Based on the EBSD analysis of the as-received specimen in Figure 1, we found that the $\alpha+\beta$ dual-phase Ti alloy consisted of equiaxed $\alpha_{p}$ with an average size of about $10 \mu \mathrm{m}$ and lamellar secondary $\alpha$ phases $\left(\alpha_{s}\right)$ with a thickness of about $0.9 \mu \mathrm{m}$. The amounts of $\alpha$ and $\beta$ phases were $80.3 \%$ and $18.9 \%$, respectively, which are identified in red and blue, respectively. The high-angle grain boundaries among the colony structures of the as-received specimen were constructed by $\alpha$ and $\beta$ phases. The amount of these equiaxed $\alpha_{\mathrm{p}}$ grains were about $85 \%$ without forming texture.

(a)

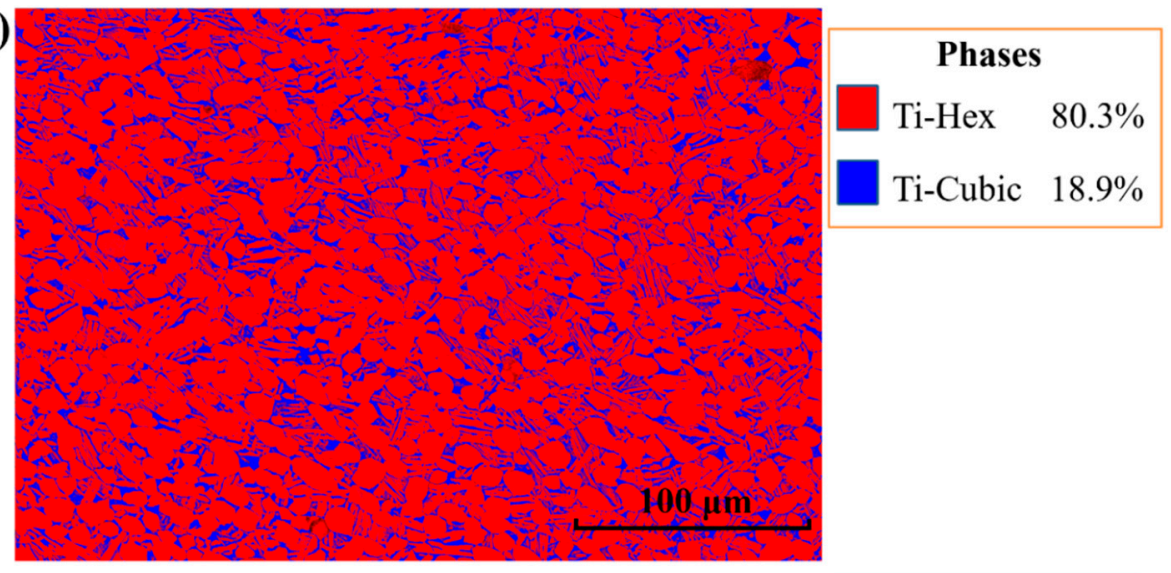

(b)

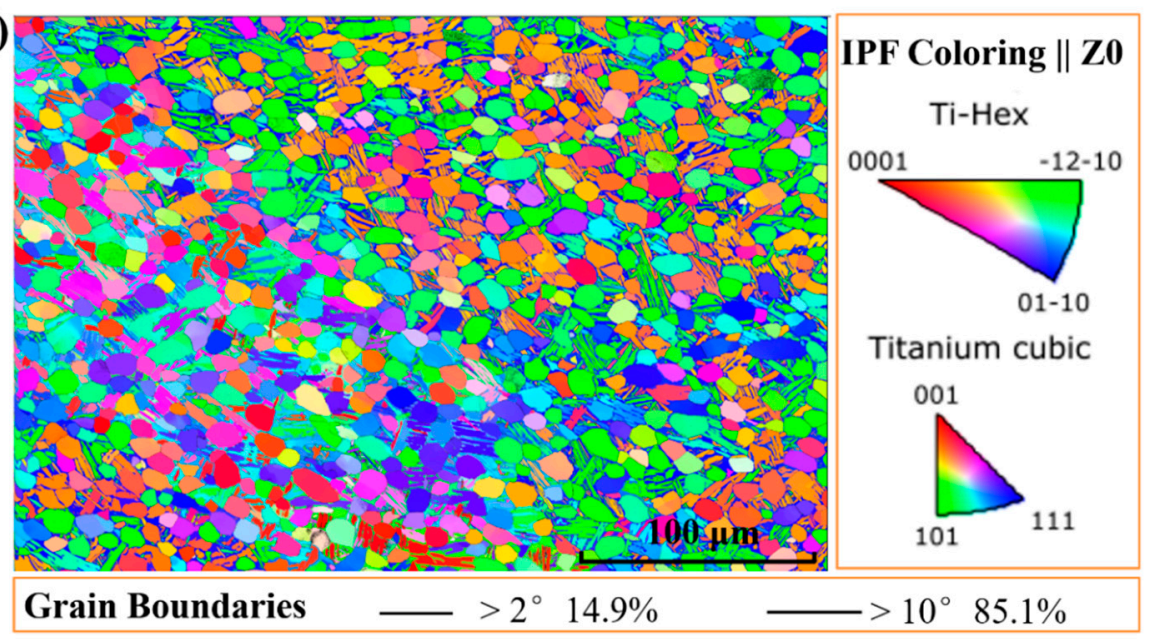

Figure 1. The electron backscattered diffraction (EBSD) analysis of the as-received dual-phase Ti alloy, (a) phase map; (b) the coupling analysis of inverse pole figure and the grain boundary map.

\subsection{Mechanical Response at High Strain Rate}

Based on the geometry of the hat-shaped specimen, the force applied to the shear region of the hat-shaped specimen in the SHPB test was obtained from the strain gauges on the incident and transmitted bars. The following equations [35] were used to calculate the shear stress $\tau_{s}$, shear strain $\gamma_{s}$, and shear strain rate $\dot{\gamma}_{s}$ within the shear region:

$$
\tau_{s}(t)=\frac{E_{0} A_{b}}{A_{s}} \varepsilon_{t}
$$




$$
\begin{gathered}
\gamma_{s}=-\frac{C_{0}}{d_{1}-d_{0}} \int_{0}^{t}\left(\varepsilon_{i}-\varepsilon_{t}\right) d t \\
\dot{\gamma}_{s}=\frac{C_{0}}{d_{1}-d_{0}}\left(\varepsilon_{i}-\varepsilon_{t}\right)
\end{gathered}
$$

where $d_{0}$ and $d_{1}$ are the outside diameter of the hat and the inner diameter of the brim ring of specimen, respectively; $C_{0}$ and $E_{0}$ are the elastic wave speed and elastic modulus of Hopkinson bars, respectively; $A_{s}$ and $A_{b}$ are the area of shear section in the hat-shaped specimen and the area of cross-section in the transmitted bar, respectively; and $\varepsilon_{i}$ and $\varepsilon_{t}$ are the elastic strains of incident and transmitted bars, respectively.

At the strain rate of $1.8 \times 10^{4} \mathrm{~s}^{-1}$, this alloy presented an excellent damage tolerance capability, which had a maximum shear stress as high as 2 GPa at the strain-hardening stage, as shown in Figure 2. It can also be seen that this stress-strain curve consisted of four stages, including an elastic region, strain hardening, stable softening, and unstable softening. In particular, the shear stress increased with increased shear strain, and reached a maximum as high as $1951 \mathrm{MPa}$ with a shear strain of 1.27, presenting an ultra-strong behavior compared with the classical high-strength Ti alloys. In the range of shear strain from 1.27 to 1.60 , the shear stress slowly decreased by $104 \mathrm{MPa}$ from the peak, attributed to the thermal softening during the adiabatic shear. The dynamic stored deformation energy until the work-hardening stage can be characterized as the integration of the stress-strain curve [36], which is much larger than those obtained from the static test. Correspondingly, it was expected that dynamic recrystallization would occur and result in the following softening. Moreover, the adiabatic shear behavior related to the microstructure evolution was revealed comprehensively, which is considered to be driven by the aforementioned stored energies.

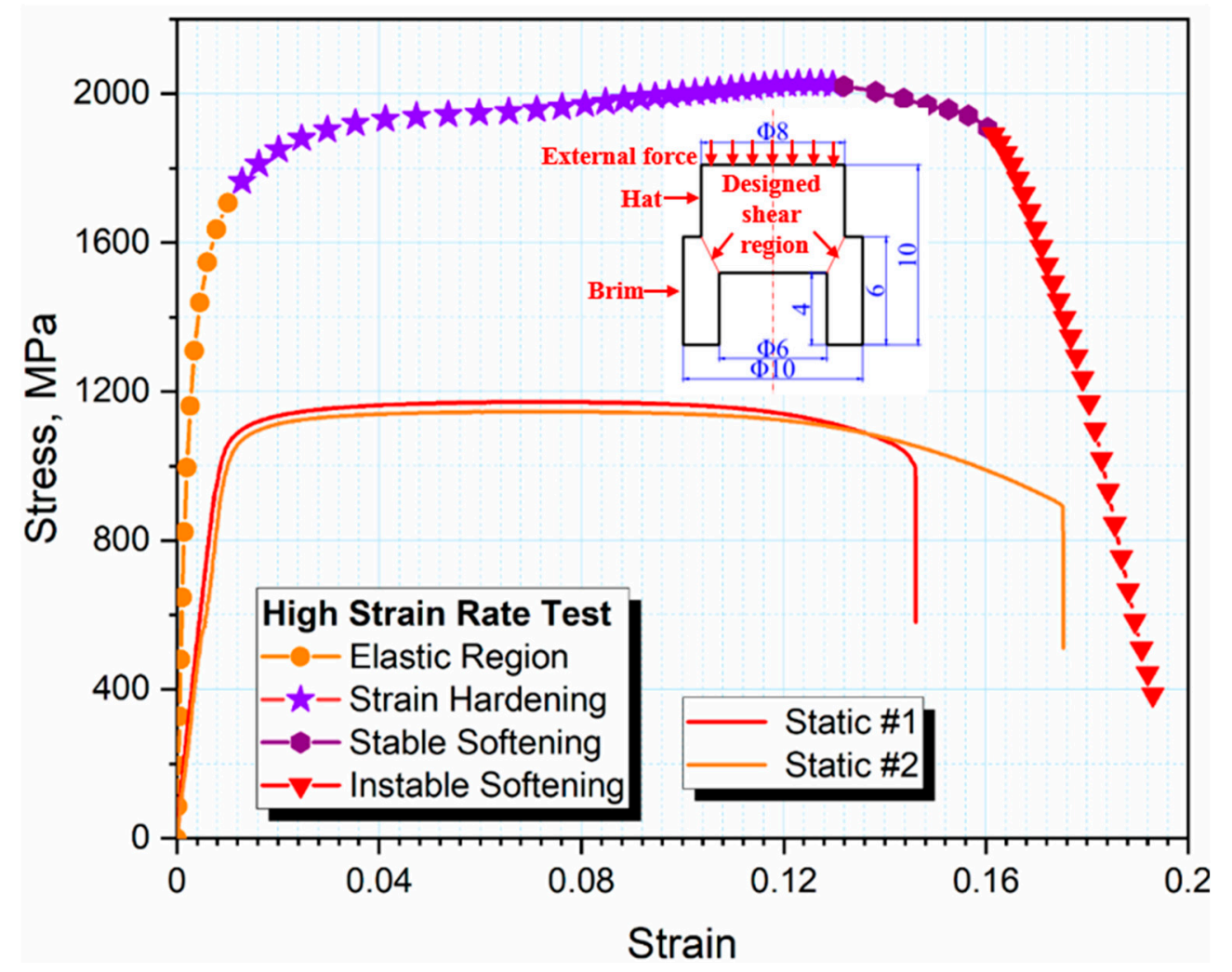

Figure 2. The stress-strain of dual-phase Ti alloy at the strain rate of $1.8 \times 10^{4} \mathrm{~s}^{-1}$ and the static one $\left(0.001 \mathrm{~s}^{-1}\right)$ together with the geometry of the hat-shaped specimen. 


\subsection{Local Features of Adiabatic Shear Bands}

In order to comprehensively reveal these stable and unstable softening mechanisms, multi-scale characterizations of the localized ASBs were essential, the typical features of which are displayed in Figure 3. The ASBs were mainly located at the $\alpha / \beta$ dual-phase colony structures, yielding severe plastic deformations along the $\alpha / \beta$ phase boundaries. This contributed to the formations of microvoids and cracks, thus resulting in stable and unstable softening behaviors. Moreover, these ASBs caused by the thermal softening and the stress concentrations were the preferred sites for nucleation, growth, and coalescence of microvoids, contributing to the formation of cracks in the ASBs after reaching the critical length [37]. Interestingly, these microvoids were generally located at the center of the ASBs, which are attributed to the gradients of temperature and stress from the center of the ASBs to the boundary of matrix [37]. Furthermore, there were several well-aligned parallel ASBs, constructing the primary and the subordinate shear paths/zones. Even within the primary shear path, it seemed as if these shear bands formed periodically were caused by the thermoplastic instability/softening, which highlights the significance of geometry and microstructures dominated by the shear angle, shear strain, and shear rate [38].
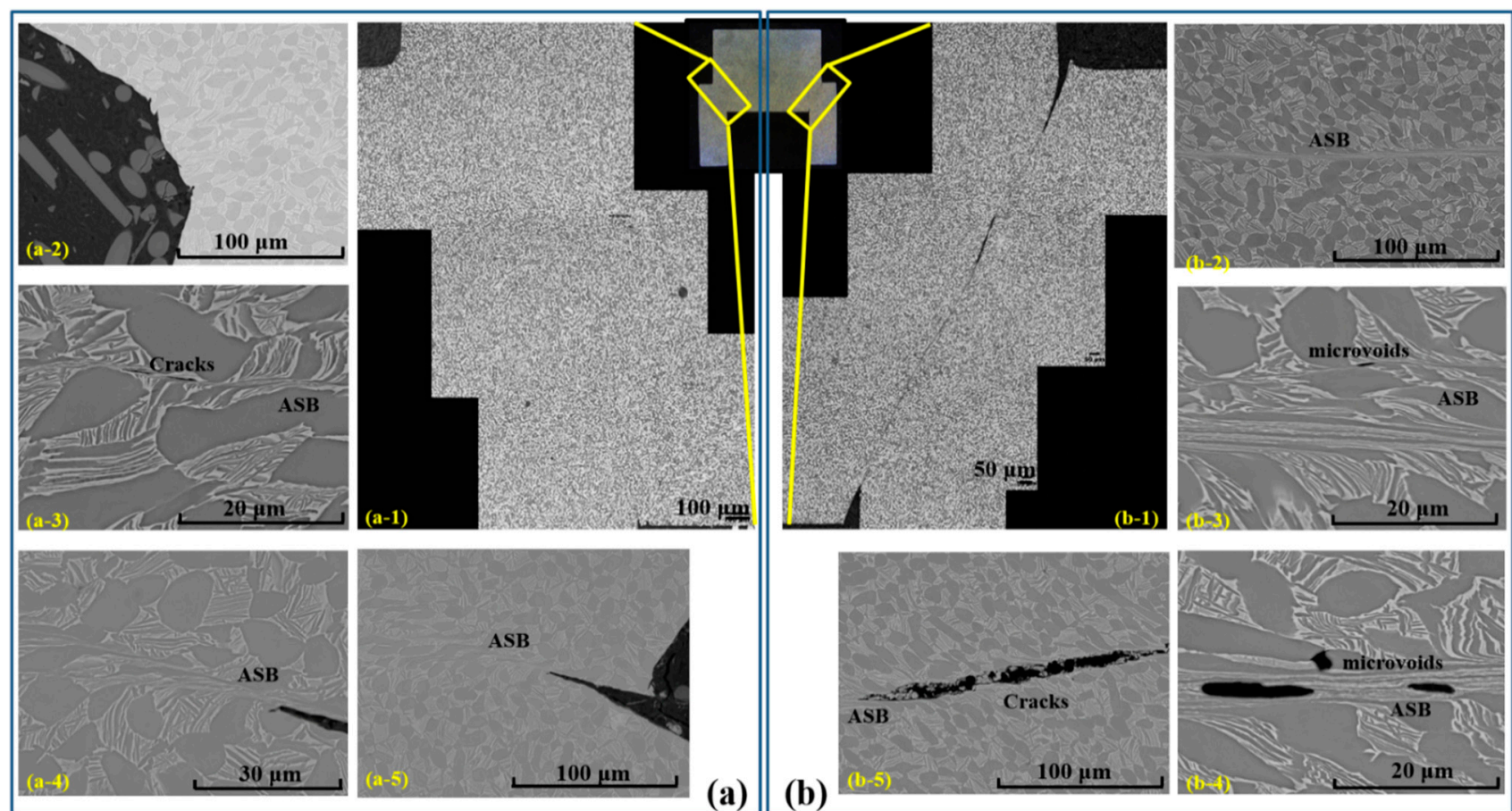

(a)

(b)
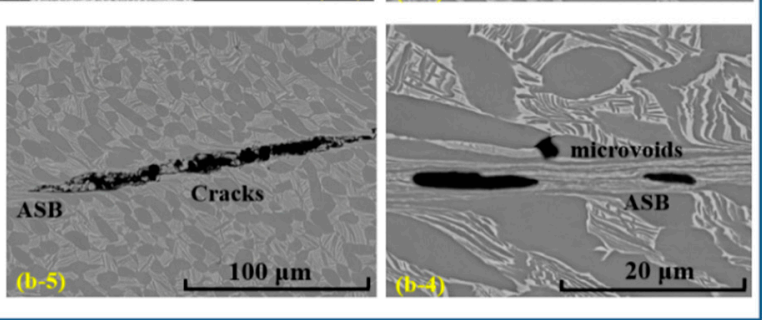

Figure 3. The multi-scale SEM characterizations of adiabatic shear bands in the hat-shaped specimen. The left part and the right part of the weak areas in the hat-shaped specimen are marked by yellow frames in (a-1) and (b-1), respectively. $(\mathbf{a}-2) \sim(\mathbf{a}-5)$ reflect the typical features of the selected right region, such as ASB, microvoids and $\alpha+\beta$ phases, while the selected left region is identified in (b-2) (b-5).

Figure 4 shows the full scans of the ASBs and the corresponding affected zones in terms of the phase map, the geometrically necessary dislocation (GND )map, and the coupling analysis of inverse pole figure and grain boundary map (IPF+GB). Different plastic strains between the left and the right sections may also yield different microstructure evolutions. In the phase maps, the estimated amounts of $\beta$ phase decreased to less than $10 \%$, which also indicates that the dominated shearing path was along the $\alpha / \beta$ phase boundaries, which caused the $\beta$ grains within the elongated and the recrystallized extremely fine $\alpha$ grains to be indistinguishable. Dynamic recrystallization yielded a large amount of fine $\alpha$ grains dispersed along the shearing paths and in the ASBs, which could contribute to the formation of textures. It is understood that recrystallization is dominated by the entropic effect arising from the competition between the formation of dislocation and that 
of grain boundaries while the shear band instability emerges, which is attributed to the thermal heating occurring faster than heat dissipation [39]. Moreover, the thickness of the ASB-affected regions resulting in the collaborating plastic deformation was clearly captured by GND mapping. It seems as if the low-angle grain boundaries of the left side presented a good resistance to the formation of cracks and the thermal softening. The grain boundaries with high angles within the ASBs were also geometrical necessary boundaries, which is the same as previous observations in pure Ti [40]. In line with the grain boundary complexions [41-43], it is understood that free volumes exist at the boundaries, constructing the weakly bonded regions and contributing to the initiation of ASBs. Furthermore, the $\{0001\}\langle 11 \overline{2} 0\rangle$ slip systems highlighted in red in the IPF maps play an important role in the formation of ASBs, which is validated by the following theoretical analysis.

Full scan of left side

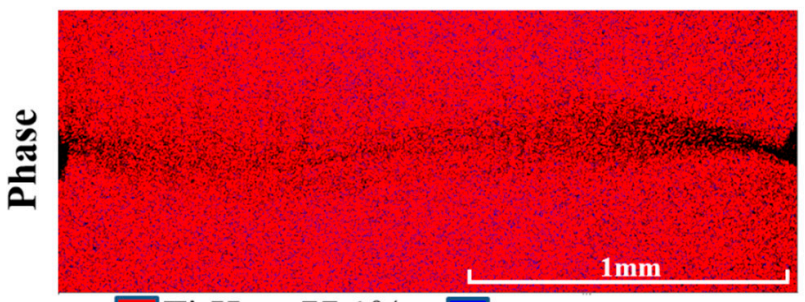

Ti-Hex $77.1 \% \square$ Ti-Cubic 9.3\%

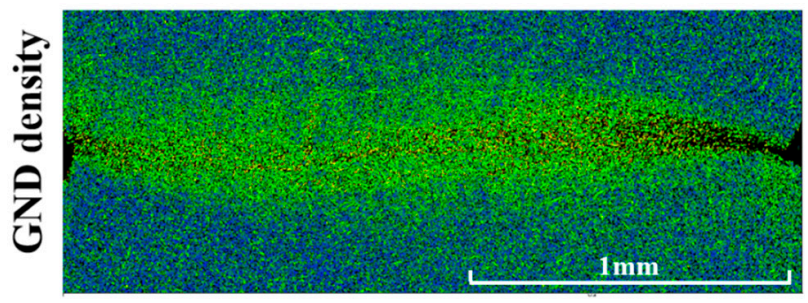

Ti-Hex 0.03

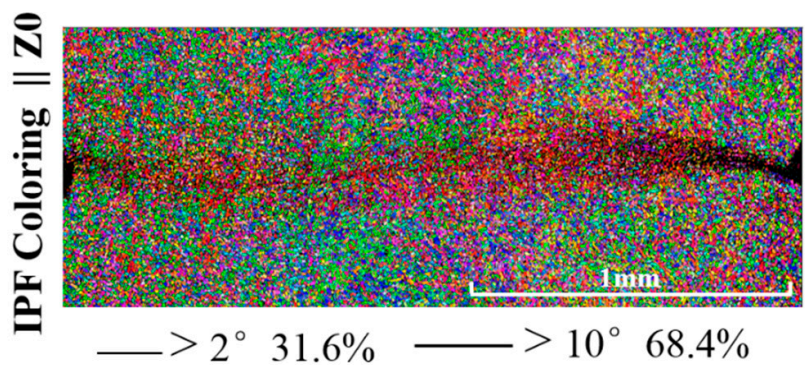

Full scan of right side

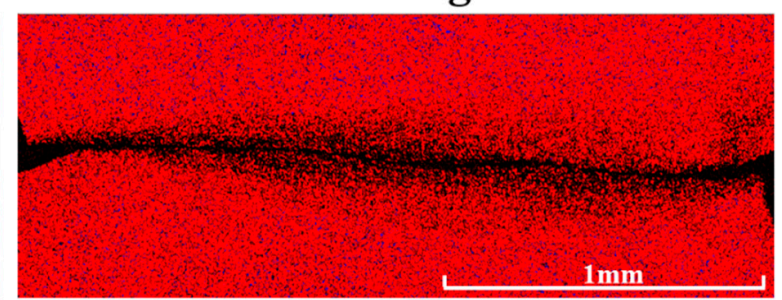

Ti-Hex $71.3 \% \square$ Ti-Cubic $4 \%$

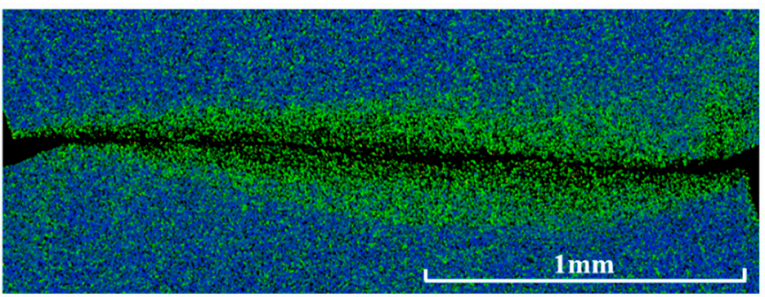

Ti-Hex

0

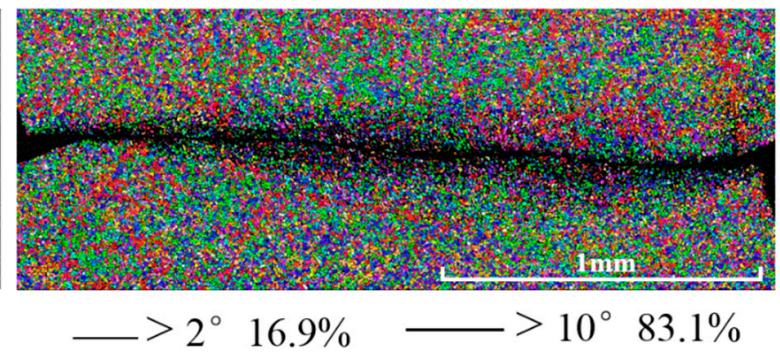

Ti-Hex

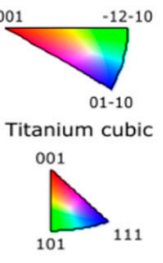

Figure 4. The EBSD features of the hat-shaped specimens in terms of phase map ( $\mathrm{Ph}$ ), geometrically necessary dislocation (GND) map, and the coupling analysis of inverse pole figure and grain boundary map (IPF+GB).

As displayed in Figure 5, the $\alpha$ grains were elongated while the $\beta$ grains were difficult to capture in the colony structures. The solid and dashed arrows identify the cracks and the elongated $\alpha$ phase, respectively. It is understood that rotational dynamic recrystallization (RDR) yields a large amount of fine equiaxed $\alpha$ grains dispersed along the shearing paths and in ASBs, promoting the aforementioned stable softening and shear localization [20,36]. The equiaxed grains could be re-elongated by further deformation. In line with the progressive subgrain misorientation recrystallization, a mechanical subgrain rotation model to account for the recrystallized grains has been proposed and observed in ASBs in a number of materials $[32,33,44]$. The mechanical subgrain rotations at a high strain rate would assist the mechanism of recrystallizations. Recently, it was reported that the initiation of ASBs will occur ahead of the apparent temperature rise in Ti $[23,24]$, motivating further investigation of the traditional well-accepted thermal-softening mechanism of ASBs. Thus, 
the local microstructure evolutions caused by shearing lead to dynamic recrystallizations and play an important role of softening during severe plastic deformation.

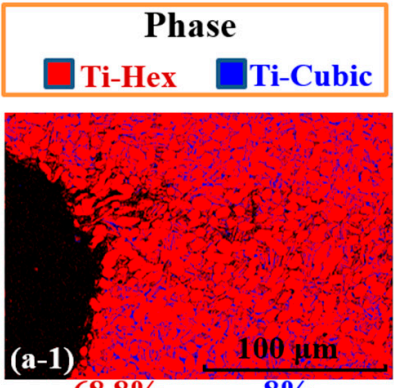

$68.8 \%$

(b)

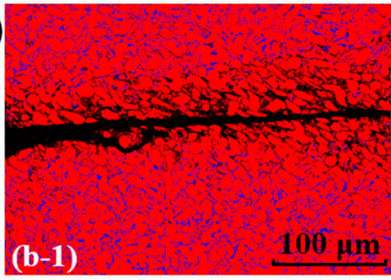

(c)

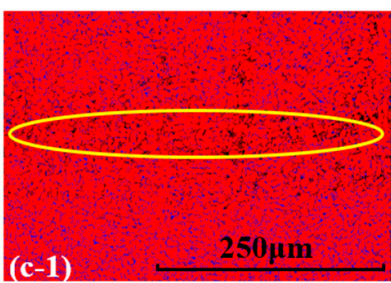

(d)

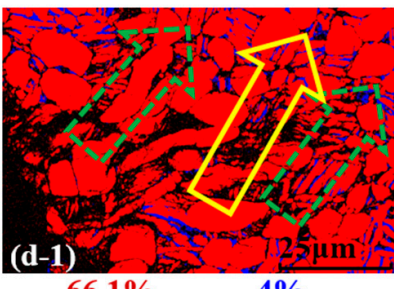

$66.1 \%$

(e)

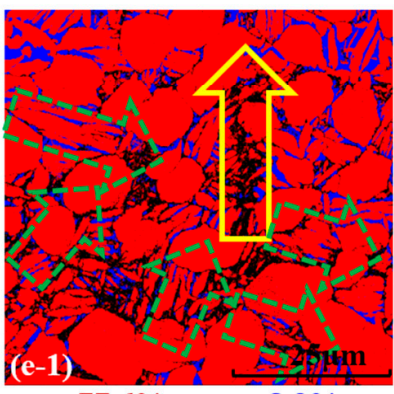

$77.6 \%$

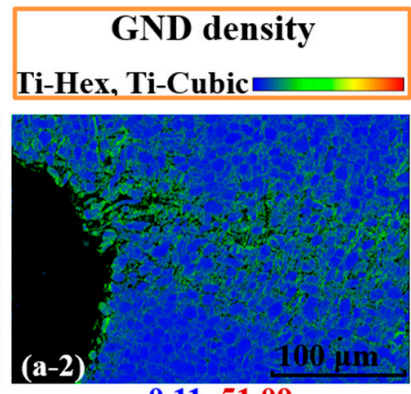

0.11 51.09

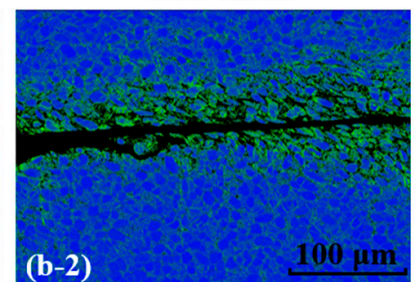

0 51.17

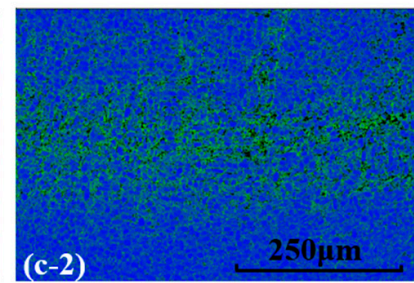

0 34.09

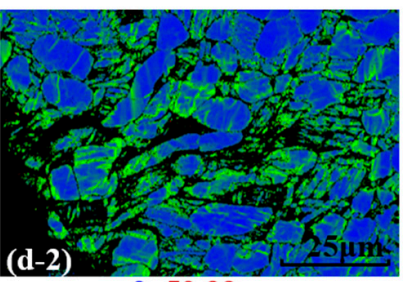

0 50.99

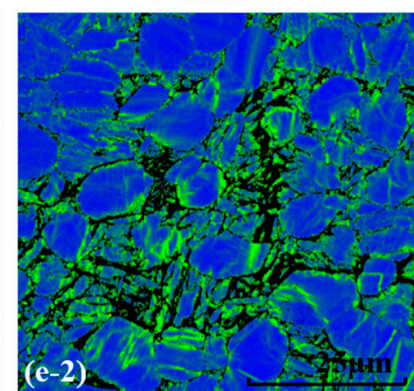

$0.28 \sim 51.08$
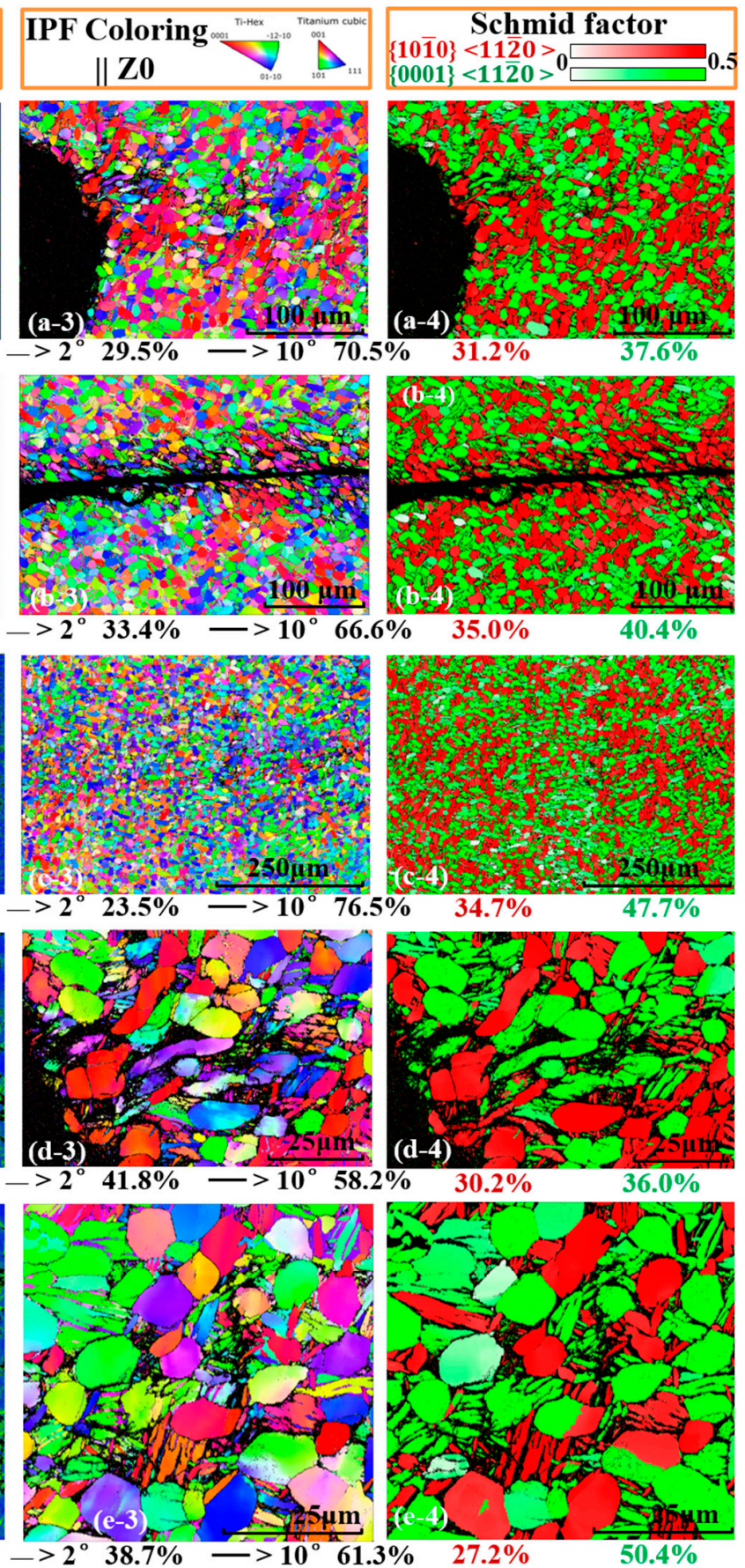

Figure 5. The typical features of ASBs and the affected zones in views of the phase map, GND map, and IPF+GB: (a-c) the cracks and ASB shear paths; (d,e) the localized shear deformation areas together with solid and dashed arrows identifying the cracks and the elongated $\alpha$ phase, respectively.

\subsection{Discussion}

During shock loading, uncommon slip systems might be activated. In general, plastic deformation initiates on the crystallographic plane with the highest Schmid factor when the stress resolved on that plane in the slip direction reaches a critical value. Based on the experimental analysis of Schmid factor, as shown in Figures 5 and $6 \mathrm{a}, \mathrm{b}$, the basal and the prismatic slips mediated by $\{0001\}\langle 11 \overline{2} 0\rangle$ and $\{10 \overline{1} 0\}\langle 11 \overline{2} 0\rangle$ are the dominated 
slip systems. Therefore, the physical reasons for the selection of these two slip systems are essential, which can also verify whether the Schmid law breaks down. Under the condition of $|\cos \lambda(a, b, c)| \leq 1$, the SF of a given slip direction $<\mathrm{a}, \mathrm{b}, \mathrm{c}>$ can be screened comprehensively. As displayed in Figure $6 c, d$, although the pyramidal slip systems have the largest SFs compared with those of basal and prismatic ones within the low angle ranges, they are difficult to activate because of the requirements of the largest critical resolved shear stress and the rotations of deformed grains. On the contrary, in the range of $25 \sim 35^{\circ}$, the basal and prismatic slips are the dominant approaches since both of them have the larger SFs, matching well with the present experimental observations. Since non-basal slipping enhances both the strength and ductility of an HCP structure [45], the $\{10 \overline{1} 0\}\langle 11 \overline{2} 0\rangle$ prismatic slips dramatically contribute to the aforementioned strain hardening. Finally, it is highlighted that the Schmid or the non-Schmid behaviors of the materials should be comprehensively investigated, revealing the variations in critical resolved shear stress and the selections of deformation model $[18,26,46]$, providing the promising strategies to enhance damage tolerance properties.

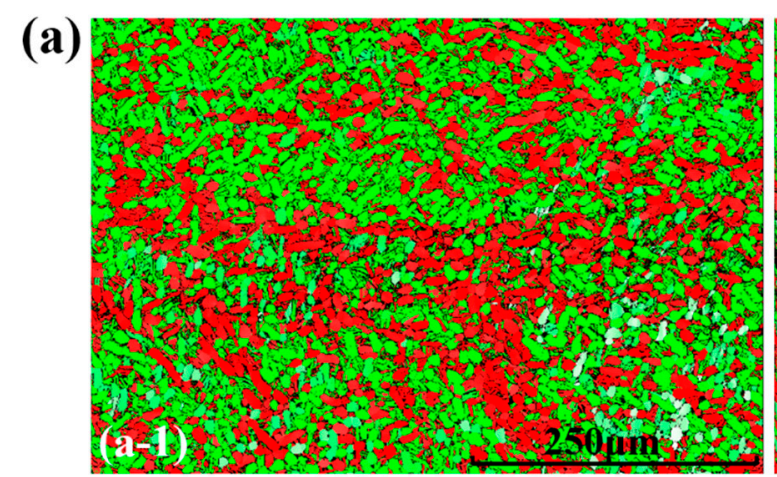

$$
34.0 \% \quad 48.2 \%
$$

(b)

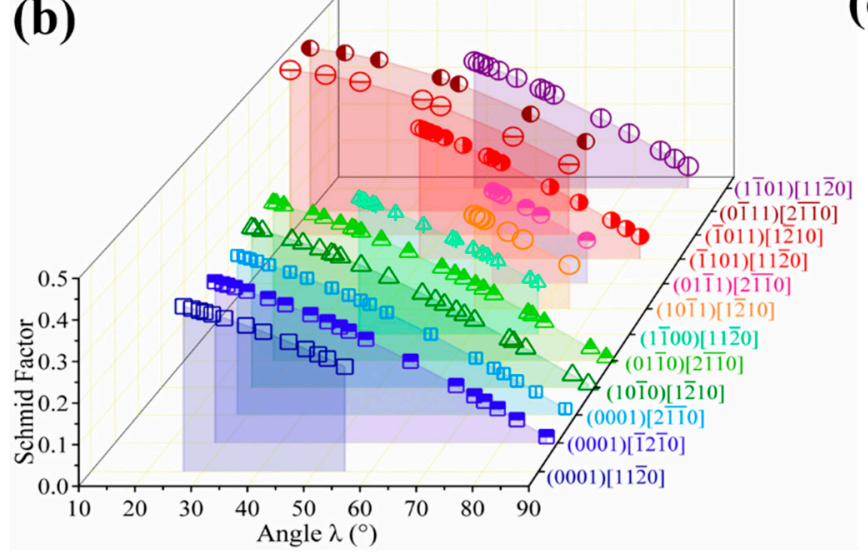

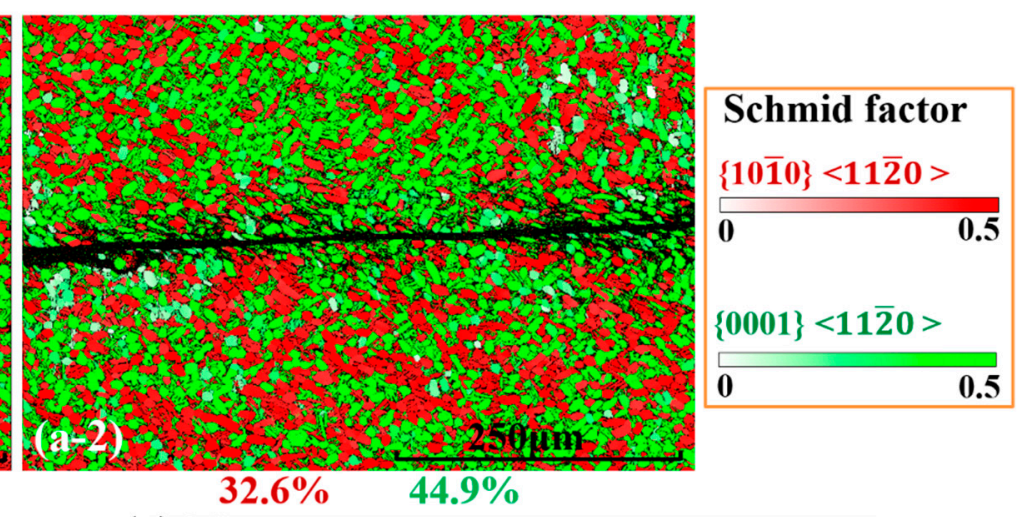

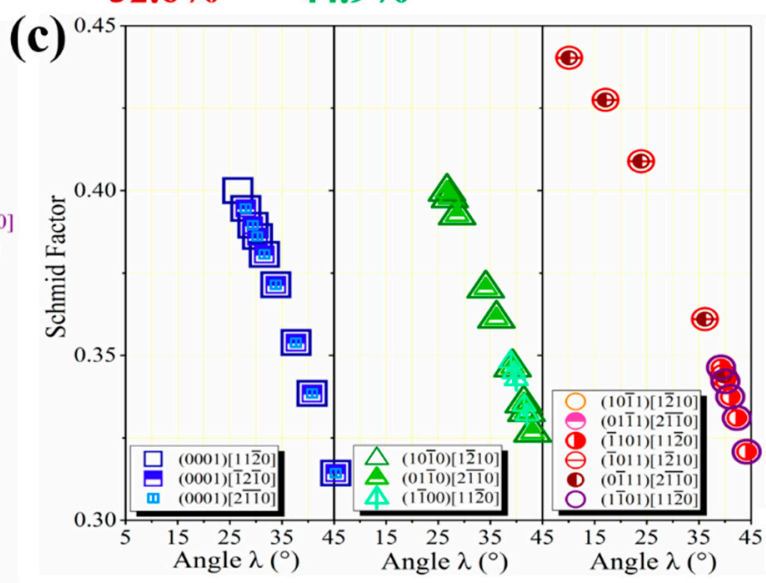

Figure 6. The theoretical Schmid factors (SFs) referring to experimental observations: (a) experimental characterizations of SFs of the left and the right side of the hat-shaped specimen; $(\mathbf{b}, \mathbf{c}) 3 \mathrm{D}$ and 2D views of the theoretical SFs.

\section{Conclusions}

In summary, the $\alpha+\beta$ dual-phase colony structures mediate the extensive plastic deformations along $\alpha / \beta$ phase boundaries, which contribute to the formations of ASBs, microvoids, and cracks, thus resulting in stable and unstable softening behaviors. Dynamic recrystallization yields a large amount of fine $\alpha$ grains dispersed along the shearing paths and in ASBs, promoting the softening and shear localization. On the contrary, the low-angle grain boundaries present a good resistance to the formation of cracks and thermal softening, while the non-basal slipping dramatically contributes to strain hardening, supporting the promising approaches to fabricating advanced damage-tolerant dual-phase Ti alloy. 
Author Contributions: Conceptualization, F.H., K.W., X.L., H.S., Y.F. and J.L.; methodology, F.H., Y.M., D.L., X.G. and W.Y.W.; validation, Y.D., Y.M., D.L., X.G. and W.Y.W.; formal analysis, F.H., P.L., Y.M., J.W., Y.D. and W.Y.W.; investigation, F.H., P.L., Y.M., J.W., Y.D. and W.Y.W.; data curation, F.H.; Y.D., Y.M., W.Y.W.; writing—original draft preparation, F.H., P.L., Y.M., J.W., Y.D. and W.Y.W.; writing-review and editing, K.W., X.L., H.S., Y.F. and J.L.; visualization, F.H., P.L., Y.M., Y.D. and W.Y.W.; supervision, K.W., X.L., H.S., Y.F. and J.L.; project administration, W.Y.W., H.S. and F.H.; funding acquisition, W.Y.W., H.S. and F.H. All authors have read and agreed to the published version of the manuscript.

Funding: This research was funded by the Science Challenge Project, grant number TZ2018002, and the Western Superconducting Technologies Co., Ltd., EPRCTC project 41422010505. The APC was funded by the Western Superconducting Technologies Co., Ltd., EPRCTC project 41422010505.

Data Availability Statement: Correspondence and requests for data and materials should be addressed to W.Y.W. (wywang@nwpu.edu.cn) and Y.X.D. (Eason@c-wst.com).

Acknowledgments: The authors acknowledge the financial supports by the Science Challenge Project (TZ2018002) and the Western Superconducting Technologies Co., Ltd. (EPRCTC project 41422010505).

Conflicts of Interest: The authors declare no conflict of interest.

\section{References}

1. Yu, Q.; Shan, Z.-W.; Li, J.; Huang, X.; Xiao, L.; Sun, J.; Ma, E. Strong crystal size effect on deformation twinning. Nature 2010, 463, 335-338. [CrossRef]

2. Clouet, E.; Caillard, D.; Chaari, N.; Onimus, F.; Rodney, D. Dislocation locking versus easy glide in titanium and zirconium. Nat. Mater. 2015, 14, 931-936. [CrossRef] [PubMed]

3. Polmear, I.; StJohn, D.; Nie, J.-F.; Qian, M. Chapter 7-Titanium Alloys. In Light Alloys, 5th ed.; Butterworth-Heinemann: Boston, MA, USA, 2017; pp. 369-460. [CrossRef]

4. Li, X.; Lu, K. Playing with defects in metals. Nat. Mater. 2017, 16, 700-701. [CrossRef] [PubMed]

5. Kaplan, W.D. The mechanism of crystal deformation. Science 2015, 349, 1059-1060. [CrossRef] [PubMed]

6. Zhang, Y.; Li, J.; Wang, W.Y.; Li, P.; Tang, B.; Wang, J.; Kou, H.; Shang, S.; Wang, Y.; Kecskes, L.J.; et al. When a defect is a pathway to improve stability: A case study of the $\mathrm{L}_{2} \mathrm{Co}_{3} \mathrm{TM}$ superlattice intrinsic stacking fault. J. Mater. Sci. 2019, 54, 13609-13618. [CrossRef]

7. Wang, W.Y.; Tang, B.; Shang, S.-L.; Wang, J.; Li, S.; Wang, Y.; Zhu, J.; Wei, S.; Wang, J.; Darling, K.A.; et al. Local lattice distortion mediated formation of stacking faults in Mg alloys. Acta Mater. 2019, 170, 231-239. [CrossRef]

8. Bae, J.W.; Lee, J.; Zargaran, A.; Kim, H.S. Enhanced cryogenic tensile properties with multi-stage strain hardening through partial recrystallization in a ferrous medium-entropy alloy. Scr. Mater. 2021, 194, 113653. [CrossRef]

9. Wu, G.; Chan, K.-C.; Zhu, L.; Sun, L.; Lu, J. Dual-phase nanostructuring as a route to high-strength magnesium alloys. Nature 2017, 545, 80-87. [CrossRef]

10. Basu, S.; Li, Z.; Pradeep, K.G.; Raabe, D. Strain rate sensitivity of a TRIP-assisted dual-phase high-entropy alloy. Front. Mater. 2018, 5, 30. [CrossRef]

11. Zou, C.; Li, J.; Wang, W.Y.; Zhang, Y.; Lin, D.; Yuan, R.; Wang, X.; Tang, B.; Wang, J.; Gao, X.; et al. Integrating data mining and machine learning to discover high-strength ductile Titanium alloys. Acta Mater. 2021, 202, 211-221. [CrossRef]

12. Mantri, S.A.; Choudhuri, D.; Alam, T.; Viswanathan, G.B.; Sosa, J.M.; Fraser, H.L.; Banerjee, R. Tuning the scale of $\alpha$ precipitates in $\beta$-titanium alloys for achieving high strength. Scr. Mater. 2018, 154, 139-144. [CrossRef]

13. Lee, S.W.; Park, C.H.; Hong, J.-K.; Yeom, J.-T. Development of sub-grained $\alpha+\beta$ Ti alloy with high yield strength showing twinning- and transformation-induced plasticity. J. Alloys Compd. 2020, 813, 152102. [CrossRef]

14. Danard, Y.; Poulain, R.; Garcia, M.; Guillou, R.; Thiaudiere, D.; Mantri, S.; Banerjee, R.; Sun, F.; Prima, F. Microstructure design and in-situ investigation of TRIP/TWIP effects in a forged dual-phase Ti-10V-2Fe-3Al alloy. Materialia 2019, 8, 100507. [CrossRef]

15. Kloenne, Z.; Viswanathan, G.; Fox, S.; Loretto, M.; Fraser, H.L. Interface and colony boundary sliding as a deformation mechanism in a novel titanium alloy. Scr. Mater. 2020, 178, 418-421. [CrossRef]

16. Bertrand, E.; Castany, P.; Péron, I.; Gloriant, T. Twinning system selection in a metastable $\beta$-titanium alloy by Schmid factor analysis. Scr. Mater. 2011, 64, 1110-1113. [CrossRef]

17. Wang, L.; Eisenlohr, P.; Yang, Y.; Bieler, T.R.; Crimp, M.A. Nucleation of paired twins at grain boundaries in titanium. Scr. Mater. 2010, 63, 827-830. [CrossRef]

18. Qin, H.; Jonas, J.J. Variant selection during secondary and tertiary twinning in pure titanium. Acta Mater. 2014, 75, 198-211. [CrossRef]

19. Reddy, V.S.; Nath, P.; Horbach, J.; Sollich, P.; Sengupta, S. Nucleation theory for yielding of nearly defect-free crystals: Understanding rate dependent yield points. Phys. Rev. Lett. 2020, 124, 025503. [CrossRef] [PubMed]

20. Rittel, D.; Landau, P.; Venkert, A. Dynamic recrystallization as a potential cause for adiabatic shear failure. Phys. Rev. Lett. 2008, 101, 165501. [CrossRef] 
21. Ma, X.; Zhao, D.; Yadav, S.; Sagapuram, D.; Xie, K.Y. Grain-subdivision-dominated microstructure evolution in shear bands at high rates. Mater. Res. Lett. 2020, 8, 328-334. [CrossRef]

22. Bisht, A.; Kumar, S.; Pang, K.H.; Zhou, R.X.; Roy, A.; Silberschmidt, V.V.; Suwas, S. Shear band widening mechanism in Ti-6Al-4V under high strain rate deformation. J. Mater. Res. 2020, 35, 1623-1634. [CrossRef]

23. Guo, Y.; Ruan, Q.; Zhu, S.; Wei, Q.; Lu, J.; Hu, B.; Wu, X.; Li, Y. Dynamic failure of titanium: Temperature rise and adiabatic shear band formation. J. Mech. Phys. Solids 2020, 135, 103811. [CrossRef]

24. Guo, Y.; Ruan, Q.; Zhu, S.; Wei, Q.; Chen, H.; Lu, J.; Hu, B.; Wu, X.; Li, Y.; Fang, D. Temperature rise associated with adiabatic shear band: Causality clarified. Phys. Rev. Lett. 2019, 122, 015503. [CrossRef] [PubMed]

25. El-Azab, A. The statistical mechanics of strain-hardened metals. Science 2008, 320, 1729-1730. [CrossRef] [PubMed]

26. Arul Kumar, M.; Wronski, M.; McCabe, R.J.; Capolungo, L.; Wierzbanowski, K.; Tome, C.N. Role of microstructure on twin nucleation and growth in HCP titanium: A statistical study. Acta Mater. 2018, 148, 123-132. [CrossRef]

27. Fan, X.G.; Jiang, X.Q.; Zeng, X.; Shi, Y.G.; Gao, P.F.; Zhan, M. Modeling the anisotropy of hot plastic deformation of two-phase titanium alloys with a colony microstructure. Int. J. Plast. 2018, 104, 173-195. [CrossRef]

28. Tang, B.; Tang, B.; Han, F.; Yang, G.; Li, J. Influence of strain rate on stress induced martensitic transformation in beta solution treated TB8 alloy. J. Alloys Compd. 2013, 565, 1-5. [CrossRef]

29. Zhan, H.; Wang, G.; Kent, D.; Dargusch, M. The dynamic response of a metastable $\beta$ Ti-Nb alloy to high strain rates at room and elevated temperatures. Acta Mater. 2016, 105, 104-113. [CrossRef]

30. Ben Boubaker, H.; Mareau, C.; Ayed, Y.; Germain, G.; Tidu, A. Impact of the initial microstructure and the loading conditions on the deformation behavior of the Ti17 titanium alloy. J. Mater. Sci. 2020, 55, 1765-1778. [CrossRef]

31. Landau, P.; Osovski, S.; Venkert, A.; Gärtnerová, V.; Rittel, D. The genesis of adiabatic shear bands. Sci. Rep. 2016, 6, 37226. [CrossRef]

32. Baik, S.-I.; Gupta, R.K.; Kumar, K.S.; Seidman, D.N. Temperature increases and thermoplastic microstructural evolution in adiabatic shear bands in a high-strength and high-toughness 10 wt.\% Ni steel. Acta Mater. 2021, 205, 116568. [CrossRef]

33. Lins, J.F.C.; Sandim, H.R.Z.; Kestenbach, H.J.; Raabe, D.; Vecchio, K.S. A microstructural investigation of adiabatic shear bands in an interstitial free steel. Mater. Sci. Eng. A 2007, 457, 205-218. [CrossRef]

34. Ran, C.; Chen, P.; Li, L.; Zhang, W. Dynamic shear deformation and failure of Ti-5Al-5Mo-5V-1Cr-1Fe titanium alloy. Mater. Sci. Eng. A 2017, 694, 41-47. [CrossRef]

35. Andrade, U.; Meyers, M.A.; Vecchio, K.S.; Chokshi, A.H. Dynamic recrystallization in high-strain, high-strain-rate plastic deformation of copper. Acta Metall. Mater. 1994, 42, 3183-3195. [CrossRef]

36. Osovski, S.; Rittel, D.; Landau, P.; Venkert, A. Microstructural effects on adiabatic shear band formation. Scr. Mater. 2012, 66, 9-12. [CrossRef]

37. Wang, B.F.; Yang, Y.; Chen, Z.P.; Zeng, Y. Adiabatic shear bands in alpha-titanium tube under external explosive loading. J. Mater. Sci. 2007, 42, 8101-8105. [CrossRef]

38. Yan, D.V.P.; Jin, X.L. Characterization of shear band formation and microstructure evolution during orthogonal cutting of Ti-5553: Part I-Shear angle, strain and strain rate. J. Mater. Eng. Perform. 2020, 29, 4063-4074. [CrossRef]

39. Lieou, C.K.C.; Bronkhorst, C.A. Dynamic recrystallization in adiabatic shear banding: Effective-temperature model and comparison to experiments in ultrafine-grained titanium. Int. J. Plast. 2018, 111, 107-121. [CrossRef]

40. Yang, Y.; Wang, B.F. Microstructure evolution in adiabatic shear band in $\alpha$-titanium. J. Mater. Sci. 2006, 41, 7387-7392. [CrossRef]

41. Cantwell, P.R.; Tang, M.; Dillon, S.J.; Luo, J.; Rohrer, G.S.; Harmer, M.P. Grain boundary complexions. Acta Mater. 2014, 62, 1-48. [CrossRef]

42. Dillon, S.J.; Harmer, M.P.; Luo, J. Grain boundary complexions in ceramics and metals: An overview. JOM 2009, 61, 38-44 [CrossRef]

43. Meiners, T.; Frolov, T.; Rudd, R.E.; Dehm, G.; Liebscher, C.H. Observations of grain-boundary phase transformations in an elemental metal. Nature 2020, 579, 375-378. [CrossRef]

44. Tang, L.; Chen, Z.; Zhan, C.; Yang, X.; Liu, C.; Cai, H. Microstructural evolution in adiabatic shear bands of copper at high strain rates: Electron backscatter diffraction characterization. Mater. Charact. 2012, 64, 21-26. [CrossRef]

45. Bu, Y.; Li, Z.; Liu, J.; Wang, H.; Raabe, D.; Yang, W. Nonbasal slip systems enable a strong and ductile Hexagonal-Close-Packed high-entropy phase. Phys. Rev. Lett. 2019, 122, 075502. [CrossRef] [PubMed]

46. Lim, H.; Hale, L.M.; Zimmerman, J.A.; Battaile, C.C.; Weinberger, C.R. A multi-scale model of dislocation plasticity in $\alpha$-Fe: Incorporating temperature, strain rate and non-Schmid effects. Int. J. Plast. 2015, 73, 100-118. [CrossRef] 